\title{
The Prevalence of Depression and Its Association With Quality of Life Among Pregnant and Postnatal Women in China: A Multicenter Study
}

\section{Haixin Bo}

Peking Union Medical College Hospital

YUAN YANG ( $\mathbf{3 0 6 8 5 0 4 7 5 @ q q . c o m ) ~}$

Southern Medical University Nanfang Hospital https://orcid.org/0000-0002-2914-9832

\section{Dongying Zhang}

Peking Union Medical College Hospital

\section{Meng Zhang}

Peking Union Medical College Hospital

\section{Peihong Wang}

Huazhong University of Science and Technology - Main Campus: Huazhong University of Science and Technology

\section{Xiaohua Liu}

Shuangliu district maternal and child health hospital

\section{Lina Ge}

Shengjing Hospital of China Medical University

\section{Wenxuan Lin}

Guangdong women and children hospital

Yang Xu

China-Japan Friendship Hospital

Yalan Zhang

Qinghai Provincial People's Hospital

\section{Fengjuan Li}

Maternal and child health care hospital of Uygur Autonomous region

\section{Xujuan Xu}

Nantong University

\section{Honghe Wu}

Nantong maternity and child health care hospital

\section{Todd Jackson}

University of Macau

\section{Gabor S Ungvari}

University of western Australia

\section{Teris Cheung}

The Hong Kong Polytechnic University

\section{Yutao Xiang}

University of Macau

\section{Research article}

Keywords: depressive, postnatal, pregnant, quality of life, women 
Posted Date: October 30th, 2020

DOI: https://doi.org/10.21203/rs.3.rs-97771/v1

License: (c) (i) This work is licensed under a Creative Commons Attribution 4.0 International License. Read Full License 


\section{Abstract}

Background: This study examined the prevalence of depressive symptoms (depression hereafter) and its association with quality of life (QOL) among pregnant and postnatal women in China.

Methods: In this multicenter, cross-sectional study, 1,060 pregnant and postnatal women from eight hospitals were assessed. Depression and QOL were measured using standardized instruments.

Results: The prevalence of depression was 7.45\% (95\% Cl: 5.87\%-9.04\%) in the sample. Women with depression had lower QOL in physical, psychological, social and environmental domains compared to those without. Women with physical comorbidities were more likely to suffer from depression ( $\mathrm{OR}=2.391,95 \% \mathrm{Cl}=1.384-4.130, P=0.002)$.

Conclusion: Due to its negative association with QOL, increased attention should be paid to depression in pregnant and postnatal women. Regular screening assessment and preventive measures should be adopted to reduce risk of depression in this population.

\section{Introduction}

Pregnancy is characterized by multiple hormonal and anatomical changes that are associated with high risk of mental health problems such as irritability, sleep disturbances, depression and even suicidality [1, 2]. Studies have found that depressive symptoms (referred to as depression hereafter) are more prevalent among pregnant and postnatal women than women with physical problems such as preeclampsia, preterm childbirth and gestational diabetes [3]. However, depression during pregnancy and the postnatal period has often been unrecognized by clinicians because it has parallels with certain pregnancy symptoms such as loss of appetite and energy, tiredness, and libido changes [4].

In order to reduce the risk of depression during pregnancy and the postnatal period and its negative impact on health outcomes, researchers should examine its epidemiology and correlates. A meta-analysis revealed that the overall prevalence of depression in pregnant and postnatal women was $11.9 \%$ (95\% Cl: 11.4\%-12.5\%) [5]. Another meta-analysis revealed that the overall prevalence of postpartum depression among healthy mothers was $17 \%$ (95\% $\mathrm{Cl}$ : 15-20\%) [6]. A range of demographic and socio-demographic factors are associated with depression during pregnancy and the postnatal phase. For instance, researchers have found that older age, lower socioeconomic status, poorer relationships with family, intimate partner violence and unplanned pregnancy are risk factors for depression among pregnant and postnatal women [3, 7-9], while comfortable living conditions, psychological resilience, and better social support perceived by women predict reduced risk for depression [10]. In addition, sociocultural and economic contexts have significant associations with depression during pregnancy and following childbirth $[7,8]$. Therefore, its prevalence and correlates should be examined separately in different countries.

In China, some studies on depression in the perinatal period have been conducted, but findings have varied significantly, in part, because of sample differences in demographic characteristics, measurement tools, and recruitment procedures. A China-based meta-analysis revealed that the prevalence of depression during the perinatal period was $17.4 \%$ [11], but the rate decreased to $10.7 \%$ among postpartum women [12]. Common limitations of previous studies conducted in China include the reliance on single study sites, small sample sizes, and univariate rather than multivariate analyses as well as the failure to use specific measures on perinatal depression such as the Edinburgh Postnatal Depression Scale (EPDS) [11, 12]. Instead, most previous studies used generic measures of depression such as the Patient Health Questionnaire (PHQ9), Zung Self-Rating Depression Scale (SDS), and Beck Depression Inventory (BDI), all of which are less appropriate because normal postnatal experiences reflecting changes in appetite and sleep as well as loss of energy can be misconstrued as depressive symptoms on generic scales.

For several decades, quality of life (QOL) has been widely used as a comprehensive health outcome in clinical practice and research. For pregnant and postnatal women, the focus of QOL has expanded from preventing, detecting, and managing problems or complications to 'supporting psychological adaptation to pregnancy' [13]. Most past studies only examined QOL in pregnant and postnatal women with physical diseases such as gestational diabetes, and hypertension [14, 15]. In contrast, little 
is known about the association between QOL and depression in general samples of pregnant and postnatal women. Thus, we conducted this study to examine the prevalence of depression, and its demographic and clinical correlates and association with QOL among pregnant and postnatal Chinese women.

\section{Methods}

\section{Study settings and participants}

This was a multicenter, cross-sectional study conducted between February and October, 2019. Eight major hospitals in Beijing, Xinjiang, Liaoning, Guangdong, Qinghai, Hubei, Jiangsu and Sichuan provinces that are located in central, northern, southern, eastern, and western China were included to represent a range of major geographic regions in China to reduce sampling biases related to single site research and increase the sample representativeness. A consecutive patient sampling method was adopted. All women treated in Department of Obstetrics of the participating hospitals at daytime during the study period were included in this study if they met the following inclusion criteria: 1) age 18 years or older; 2) comprehension of spoken Chinese language; 3) current pregnancy or postnatal status (i.e., from the beginning of pregnancy to 1 week after delivery); 4) provision of written informed consent. Participants were excluded if they had pre-existing psychiatric disorders such as major depressive disorder, or disturbances of consciousness that can interfere with comprehension of research measures.

\section{Assessment instruments and study procedure}

Basic demographic information, including maternal age, height $(\mathrm{m})$, weight $(\mathrm{kg})$, education level, marital status, employment status, gestation, personal monthly income, history of miscarriage, placenta abruption, and physical comorbidities, were assessed on a background information form. The 10-item self-report Edinburgh Postnatal Depression Scale (EPDS) - Chinese version [16] was used to assess severity of depressive symptoms in the past week during pregnancy or the postnatal period. Total scores ranged from 0 to 30, with higher scores indicating more severe depression. An EPDS total score of 13 or above indicates 'having depression' [16]. The Chinese version of EPDS had excellent psychometric properties [17]. The World Health Organization Quality of Life Questionnaire - brief version (WHOQOL-BREF) was used to assess QOL. The WHOQOL-BREF consists of 26 items, covering physical, psychological, environmental and social QOL [18]. A higher total score indicates better QOL [19]. The Chinese version of this scale has good psychometric properties [20].

Following other studies [21, 22], three standardized 'Yes/No' questions were utilized to evaluate suicidal behaviors in the past year, including 1) suicidal ideation (SI) - 'Have you ever thought about killing yourself?', 2) Suicide plans (SP) - 'Have you ever made a plan for committing suicide, or even taken steps to prepare for this plan?', and 3) Suicide attempts (SA) - 'Have you ever attempted suicide?'. Participants who answered 'Yes' to any of the three questions were considered as 'having suicidality'.

All participants were approached by trained nurses who explained the study aim and procedure. For those who agreed to participate and provided written informed consent form, a face-to-face interview was conducted. This study was approved by the Clinical Research Ethics Committee of the Peking Union Medical College Hospital and all participating hospitals (Ref No: SK1273). All the study procedures were carried out in accordance with relevant guidelines.

\section{Sample size estimation}

The total sample size of participants was estimated using a standardized formula: $N=Z_{a}{ }^{2} P(1-P) / d^{2}[23]$. $N$ means the sample size, Z means the statistic of significance test, alpha means the significance level, $\mathrm{P}$ means the prevalence, and $d$ means the allowable error. In this study, alpha was set at $0.05, Z_{a}=1.96$, and the estimated acceptable margin of effort for proportion $d$ was 0.1 as recommended [23]. The prevalence of depression in pregnant and postnatal women was $15 \%$ in a systematic review [24], which was used for sample size calculation in this study. A minimum sample size of 490 participants were needed. To increase the statistical power, we recruited 1,100 participants in this study.

\section{Statistical analyses}


Data analyses were performed using SPSS V24.0. Normality distributions of continuous variables were checked by one-sample Kolmogorov-Smirnov tests. Differences on demographic and clinical characteristics between depression and no depression groups were assessed using independent samples t-tests for normally distributed continuous variables, Mann-Whitney $U$ tests for non-normally distributed continuous variables, and Chi-square tests/Fisher exact tests for categorical variables. Analysis of covariance (ANCOVA) was used to compare QOL between depression and no depression groups after controlling for variables on which these groups differed $(P<0.05)$ in univariate analyses. Binary logistic regression analysis based on the "enter" method was used to examine independent correlates of depression. Depression was the dependent variable, while variables on which there were significant univariate group differences were entered as independent variables. Significance was set at $P<$ 0.05 , with two-tailed tests.

\section{Results}

A total of 1,140 women were invited to participate in this study; of these, 1,060 agreed and completed the assessment, producing a response rate of $92.98 \%$. The overall prevalence of depression was $7.45 \%(95 \% \mathrm{Cl}: 5.87 \%-9.04 \%)$; within the depressed subgroup $(\mathrm{N}=79)$, the highest rate was found in the third trimester $(45.6 \%)$, followed by the first trimester $(25.3 \%)$ and second trimester (19.0\%). The lowest figure was shown among postnatal women (10.1\%). Within the entire sample, 27 (2.6\%) women reported having experiences of suicidality, with 26 (2.5\%) reporting suicidal ideation, 4 (0.38\%) reporting a suicide plan and $5(0.47 \%)$ admitting to a suicide attempt. Specifically, there were 14 women $(17.7 \%)$ with suicidality in the depression group compared to 13 women $(1.3 \%)$ in the no depression group $(P<0.001)$. Demographic and clinical characteristics are presented in Table 1. 


\begin{tabular}{|c|c|c|c|c|c|c|c|c|c|c|c|c|}
\hline \multirow{3}{*}{ Variable } & \multirow{2}{*}{\multicolumn{2}{|c|}{$\begin{array}{l}\text { Total }(N= \\
1,060)\end{array}$}} & \multirow{2}{*}{\multicolumn{2}{|c|}{$\begin{array}{l}\begin{array}{l}\text { No } \\
\text { depression }\end{array} \\
(\mathrm{N}=981)\end{array}$}} & \multirow{2}{*}{\multicolumn{2}{|c|}{$\begin{array}{l}\text { Depression } \\
(\mathrm{N}=79)\end{array}$}} & \multicolumn{3}{|c|}{ Univariate analyses } & \multicolumn{3}{|c|}{$\begin{array}{l}\text { Multivariate logistic } \\
\text { regression }\end{array}$} \\
\hline & & & & & & & \multirow[t]{2}{*}{$X^{2} / Z$} & \multirow[t]{2}{*}{ df } & \multirow[t]{2}{*}{$\mathrm{P}$} & \multirow[t]{2}{*}{ OR } & \multirow[t]{2}{*}{$95 \% \mathrm{Cl}$} & \multirow[t]{2}{*}{$P$} \\
\hline & $\mathbf{N}$ & $\%$ & $\mathbf{N}$ & $\%$ & $\mathbf{N}$ & $\%$ & & & & & & \\
\hline $\begin{array}{l}\text { Urban } \\
\text { residence }\end{array}$ & 897 & 84.6 & 834 & 85.0 & 63 & 79.7 & 1.560 & 1 & 0.212 & - & - & - \\
\hline \multicolumn{13}{|l|}{ Pregnancy } \\
\hline First trimester & 200 & 18.9 & 180 & 18.3 & 20 & 25.3 & 2.443 & 3 & 0.486 & - & - & - \\
\hline $\begin{array}{l}\text { Second } \\
\text { trimester }\end{array}$ & 235 & 22.2 & 220 & 22.4 & 15 & 19.0 & & & & & & \\
\hline $\begin{array}{l}\text { Third } \\
\text { trimester }\end{array}$ & 516 & 48.7 & 480 & 48.9 & 36 & 45.6 & & & & & & \\
\hline Postnatal & 109 & 10.3 & 101 & 10.3 & 8 & 10.1 & & & & & & \\
\hline $\begin{array}{l}\text { College and } \\
\text { above }\end{array}$ & 712 & 67.2 & 665 & 67.8 & 47 & 59.5 & 2.281 & 1 & 0.131 & - & - & - \\
\hline Employed & 655 & 61.8 & 608 & 62.0 & 47 & 59.5 & 0.191 & 1 & 0.662 & - & - & - \\
\hline $\begin{array}{l}\text { Have four and } \\
\text { more family } \\
\text { members }\end{array}$ & 526 & 49.6 & 487 & 49.6 & 39 & 49.4 & 0.002 & 1 & 0.962 & - & - & - \\
\hline $\begin{array}{l}\text { Monthly } \\
\text { Income } \geq \\
5000 \text { RMB }\end{array}$ & 509 & 48.0 & 478 & 48.7 & 31 & 39.2 & 2.635 & 1 & 0.105 & - & - & - \\
\hline First Delivery & 608 & 57.4 & 563 & 57.4 & 45 & 57.0 & 0.005 & 1 & 0.941 & - & - & - \\
\hline $\begin{array}{l}\text { Adverse } \\
\text { Pregnant } \\
\text { Experience }\end{array}$ & 140 & 13.2 & 124 & 12.6 & 16 & 20.3 & 3.697 & 1 & 0.055 & - & - & - \\
\hline $\begin{array}{l}\text { Previous } \\
\text { natural } \\
\text { miscarriage }\end{array}$ & 203 & 19.2 & 181 & 18.5 & 22 & 27.8 & 4.170 & 1 & 0.041 & 1.407 & $\begin{array}{l}0.795- \\
2.491\end{array}$ & $\begin{array}{l}0.242 \\
b\end{array}$ \\
\hline $\begin{array}{l}\text { Previous drug- } \\
\text { induced } \\
\text { abortion }\end{array}$ & 312 & 29.4 & 280 & 28.5 & 32 & 40.5 & 5.038 & 1 & 0.025 & 1.485 & $\begin{array}{l}0.885- \\
2.494\end{array}$ & $\begin{array}{l}0.135 \\
c\end{array}$ \\
\hline $\begin{array}{l}\text { Placenta } \\
\text { Preposition }\end{array}$ & 62 & 5.8 & 55 & 5.6 & 7 & 8.9 & $-a$ & - & 0.216 & - & - & - \\
\hline \multirow[t]{3}{*}{$\begin{array}{l}\text { Physical } \\
\text { comorbidity }\end{array}$} & 139 & 13.1 & 119 & 12.1 & 20 & 25.3 & 11.157 & 1 & 0.001 & 2.391 & $\begin{array}{l}1.384- \\
4.130\end{array}$ & $\begin{array}{l}0.002 \\
d\end{array}$ \\
\hline & & & & & & & \multicolumn{3}{|c|}{ Univariate analyses } & \multicolumn{3}{|c|}{ ANCOVA } \\
\hline & Mean & SD & Mean & SD & Mean & SD & $\mathbf{T}$ & df & $P$ & $F$ & df & $P$ \\
\hline Age (years) & 29.41 & 4.21 & 29.41 & 4.19 & 29.44 & 4.57 & -0.052 & 1058 & 0.959 & - & - & - \\
\hline BMI & 24.10 & 4.24 & 24.13 & 4.29 & 23.82 & 3.68 & 0.613 & 1058 & 0.540 & - & - & - \\
\hline
\end{tabular}




\begin{tabular}{|c|c|c|c|c|c|c|c|c|c|c|c|c|}
\hline \multirow[b]{2}{*}{ Physical QOL } & \multirow[b]{2}{*}{15.21} & \multirow[b]{2}{*}{2.07} & \multirow[b]{2}{*}{15.35} & \multirow[b]{2}{*}{2.02} & \multirow[b]{2}{*}{13.45} & \multirow[b]{2}{*}{1.91} & \multicolumn{3}{|c|}{ Univariate analyses } & \multicolumn{3}{|c|}{$\begin{array}{l}\text { Multivariate logistic } \\
\text { regression }\end{array}$} \\
\hline & & & & & & & 8.108 & 1058 & $\hat{0.001}$ & 60.874 & 1 & $\begin{array}{l}<.001 \\
\mathrm{e}\end{array}$ \\
\hline $\begin{array}{l}\text { Psychological } \\
\text { QOL }\end{array}$ & 15.26 & 2.44 & 15.46 & 2.34 & 12.80 & 2.21 & 9.733 & 1058 & $\hat{0} .001$ & 91.107 & 1 & $\begin{array}{l}0.001 \\
\mathrm{e}\end{array}$ \\
\hline Social QOL & 15.57 & 2.37 & 15.72 & 2.30 & 13.61 & 2.37 & 7.815 & 1058 & $\hat{0} .001$ & 57.736 & 1 & $\begin{array}{l}{ }_{\mathrm{e}}^{<} .001 \\
\mathrm{e}\end{array}$ \\
\hline $\begin{array}{l}\text { Environmental } \\
\text { QOL }\end{array}$ & 15.04 & 2.49 & 15.24 & 2.39 & 12.66 & 2.53 & 9.185 & 1058 & $\hat{0} .001$ & 81.396 & 1 & $\begin{array}{l}<.001 \\
\mathrm{e}\end{array}$ \\
\hline $\begin{array}{l}\text { EPDS Total } \\
\text { score }\end{array}$ & 5.43 & 4.40 & 4.64 & 3.44 & 15.30 & 2.64 & - & - & - & - & - & - \\
\hline \multicolumn{13}{|c|}{$\begin{array}{l}\text { Note: a: Fisher's Exact Test; b: using age, abortion by drugs, and comorbidity as covariates; c: using age, natural } \\
\text { miscarriage, and comorbidity as covariates; } \mathrm{d} \text { : using age, natural miscarriage, and abortion by drugs as covariates; e: using } \\
\text { natural miscarriage, abortion by drugs, and comorbidity as covariates; BMI = Body mass index; Cl = Confident Interval; } \\
\text { EPDS = Edinburgh Postnatal Depression Scale; QOL = Quality of life; }\end{array}$} \\
\hline
\end{tabular}

In univariate analyses, depression was significantly associated with previous natural miscarriage experiences $(P=0.041)$, druginduced abortion history $(P=0.025)$ and physical comorbidities $(P=0.001)$ which were controlled for as covariates in subsequent analyses. Women with depression had lower physical, psychological, social and environmental quality of life compared to those without (all P values $<0.001$ ) after controlling for covariates. A multivariate logistic regression analysis revealed that women with physical comorbidities were more likely to suffer from depression $(\mathrm{OR}=2.391,95 \% \mathrm{Cl}=1.384-4.130$, $P=0.002)$ (Table 1).

\section{Discussion}

Due to hormonal and anatomical changes and other factors including heavier care burdens, pregnant and postnatal women are more likely to suffer from psychological disturbances, particularly depression [25]. In this study, the prevalence of depression was $7.45 \%$ (95\% Cl: 5.87-9.04\%) among pregnant and postpartum women, a rate that was lower than estimates from recent China-based meta-analyses [11, 12]. Notably, however, rates have varied between reviews. For example, an older meta-analysis [26] found that the pooled point prevalence of perinatal depression ranged from $6.5-12.9 \%$ from the start of pregnancy to the first postpartum year; $19.2 \%$ of the depressed subgroup reported depression during the first 3 months after delivery. Conversely, another recent meta-analysis found the overall prevalence of depression in pregnant and postnatal women was $11.9 \%$ (95\% Cl: $11.4 \%-12.5 \%$ ) [5]. Discrepant rates between studies could be partly explained by different study samples, sampling methods, sample sizes, measurement tools for depression, socioeconomic backgrounds and clinical status $[5,6,26]$.

Previous studies have indicated that depression is a strong predictor of suicidality [27-29]. In this study, a relatively small proportion of women reported suicidal ideation $(2.5 \%)$, plan $(0.38 \%)$ or attempt $(0.47 \%)$ but the rate was substantially higher than those of other studies. For example, a large retrospective study from the US found that the prevalence of suicide attempts during pregnancy was $0.04 \%$ [30]. Another study from Canada reported that the prevalence of suicide attempts was $0.03 \%$ in pregnant women and $0.06 \%$ in postnatal women [31]. A study conducted in mainland China found that the prevalence of suicide attempt during pregnancy was $0.21 \%$ [32]. Reasons for the comparatively higher rate in this research are not known. However, due to differences in timeframes and measures of suicidality between studies, direct comparisons should be made with caution. The growing awareness of mental health concerns in pregnant and postnatal women, better social support networks, increased stigma related to disclosing distress, and accessibility to mental health services in major cities of China where the participating hospitals are located could contribute to the low overall prevalence of suicidality in this population. 
Nonetheless, we found that pregnant and postnatal women with depression were more likely to have suicidality compared with those without, which is consistent with previous findings [1, 33].

Additionally, our study found that participants with physical comorbidities were more likely to report depression, which also dovetails with previous findings [34, 35]. Physical comorbidities and adverse effects of treatments in pregnant and postnatal women were associated with more severe physical discomfort and impaired daily functioning, which could increase the risk of depression [34, 35].

Similar to previous findings [36], depression was significantly associated with lower QOL in all domains. The poorer QOL of depressed women could be explained by the distress/protection QOL model, in which QOL is determined by a range of protective and distressing factors [37]. QOL tends to be lower if distressing factors (e.g., frequent sleep disturbances, fatigue, and physical discomfort caused by depression) predominate overprotective factors (e.g., better social support from social networks). Depressed women often present with psychological and physical symptoms such as sadness, helplessness, cognitive impairments, body pain, insomnia, and digestive problems [38], all of which are related to lower QOL in depressed pregnant and postnatal women.

The merits of this study included its multicenter study design, large sample size, and use of a depression measure validated specifically for pregnant and postnatal depression. The main limitations should also be acknowledged. First, this was a crosssectional study, so causal associations and changes between variables over time could not be examined. Second, all results were based on self-reported data; therefore, we cannot rule out biases in recall or social desirability as influences on the data.

Third, to ensure response burdens were not excessive, variables that may be related to depression, such as social support, were not included in this study. Fourth, although a relatively large sample size and multicenter design based on different geographic regions of China were used, the needed number of eligible perinatal women was not calculated separately for each participating hospital. In addition, those with pre-existing psychiatric disorders and potential comprehension difficulties were excluded. Therefore, selection biases cannot be ruled out as influences on the data. To increase population representativeness, more costly national epidemiological surveys using multistage designs and random sampling should be conducted in China.

\section{Conclusion}

In conclusion, due to the significant associations of depression with suicidality, and lower QOL, increased attention should be paid to pregnant and postnatal women. Preventive measures, such as regular assessment and management of physical comorbidities, should be adopted to track and reduce risk of depression in this population. Timely treatment should be provided for women who experience depression during pregnancy and the postnatal period.

\section{Declarations}

\section{Funding source}

None.

\section{Acknowledgements}

None.

\section{Competing Interest}

The authors declare that they have no competing interests.

\section{Ethical Approval and Consent to participate}

This study was approved by the Clinical Research Ethics Committee of the Peking Union Medical College Hospital and all participating hospitals (Ref No: S-K1273). All participants provided informed consent form. 
Availability of data and material

The data of the investigation will be made publicly available if necessary.

Authors' Contributions

Study design: Hai-Xin Bo, Yuan Yang, Yu-Tao Xiang. Data collection, analysis and interpretation: Yuan Yang, Dong-Ying Zhang, Xiao-Meng Zhang, Pei-Hong Wang, Xiao-Hua Liu, Li-Na Ge, Wen-Xuan Lin, Yang Xu, Ya-Lan Zhang, Feng-Juan Li, Xu-Juan Xu, Hong-He Wu. Drafting of the manuscript: Yuan Yang, Teris Cheung, Yu-Tao Xiang. Critical revision of the manuscript: Todd Jackson, Gabor S. Ungvari. Approval of the final version for publication: all co-authors.

Consent for publication

Not applicable.

\section{References}

1. Gelaye B, Addae G, Neway B, Larrabure-Torrealva GT, Qiu C, Stoner L, Luque Fernandez MA, Sanchez SE, Williams MA: Poor sleep quality, antepartum depression and suicidal ideation among pregnant women. J Affect Disord 2017, 209:195-200.

2. Holden G, Corter AL, Hatters-Friedman S, Soosay I: Brief Report. A qualitative study of maternal mental health services in New Zealand: Perspectives of Maori and Pacific mothers and midwives. Asia Pac Psychiatry 2019:e12369.

3. Gluckman PD, Hanson MA, Cooper C, Thornburg KL: Effect of in utero and early-life conditions on adult health and disease. New Engl J Med 2008, 359(1):61-73.

4. Clark G: Discussing emotional health in pregnancy: the Edinburgh Postnatal Depression Scale. Br J Community Nurs 2000, 5(2):91-98.

5. Woody CA, Ferrari AJ, Siskind DJ, Whiteford HA, Harris MG: A systematic review and meta-regression of the prevalence and incidence of perinatal depression. J Affect Disord 2017, 219:86-92.

6. Shorey S, Chee CYI, Ng ED, Chan YH, Tam WWS, Chong YS: Prevalence and incidence of postpartum depression among healthy mothers: A systematic review and meta-analysis. J Psychiatr Res 2018, 104:235-248.

7. Becker M, Weinberger T, Chandy A, Schmukler S: Depression During Pregnancy and Postpartum. Curr Psychiatry Rep 2016, 18(3):32.

8. Hutchens BF, Kearney J: Risk Factors for Postpartum Depression: An Umbrella Review. J Midwifery Womens Health 2020.

9. Bhatta N, Assanangkornchai S: Patterns of domestic violence against women during pregnancy and the postpartum period in Kathmandu, Nepal. Asia Pac Psychiatry 2019, 11(1):e12342.

10. Li Y, Long Z, Cao D, Cao F: Social support and depression across the perinatal period: A longitudinal study. J Clin Nurs 2017, 26(17-18):2776-2783.

11. Lin X, Zheng, D., Lin, XF., Dai, Y.: Perinatal Depression in China: a meta-analysis (in Chinese). Fujian Medical Journal 2017, 39(05):131-133.

12. Tao J, Gong, YR., Lu, JY.: Postpartum depression in Chinese women: a meta-analysis (in Chinese). China Journal of Health Psychology 2018, 26(02):171-174.

13. Mortazavi F, Mousavi SA, Chaman R, Khosravi A: Maternal quality of life during the transition to motherhood. Iran Red Crescent Med J 2014, 16(5):e8443.

14. Bien A, Rzonca E, Kanczugowska A, Iwanowicz-Palus G: Factors Affecting the Quality of Life and the Illness Acceptance of Pregnant Women with Diabetes. Int J Environ Res Public Health 2015, 13(1):ijerph13010068.

15. Pantzartzis KA, Manolopoulos PP, Paschou SA, Kazakos K, Kotsa K, Goulis DG: Gestational diabetes mellitus and quality of life during the third trimester of pregnancy. Qual Life Res 2019, 28(5):1349-1354.

16. Cox JL, Holden JM, Sagovsky R: Detection of Postnatal Depression - Development of the 10-Item Edinburgh Postnatal Depression Scale. Brit J Psychiat 1987, 150:782-786. 
17. Zhao Y, Kane I, Wang J, Shen BB, Luo JF, Shi SX: Combined use of the postpartum depression screening scale (PDSS) and Edinburgh postnatal depression scale (EPDS) to identify antenatal depression among Chinese pregnant women with obstetric complications. Psychiat Res 2015, 226(1):113-119.

18. Harper A, Power M, Grp W: Development of the World Health Organization WHOQOL-BREF quality of life assessment. Psychol Med 1998, 28(3):551-558.

19. Skevington SM, Tucker C: Designing response scales for cross-cultural use in health care: Data from the development of the UK WHOQOL. Brit J Med Psychol 1999, 72:51-61.

20. Fang JQ, \& Hao, Y. A. : Reliability and Validity for Chinese Version of WHO Quality of Life Scale (in Chinese). Chinese Mental Health Journal 1999, 13(4):203-209.

21. Kessler RC, Berglund P, Borges G, Nock M, Wang PS: Trends in suicide ideation, plans, gestures, and attempts in the United States, 1990-1992 to 2001-2003. Jama-J Am Med Assoc 2005, 293(20):2487-2495.

22. Ma X, Xiang YT, Cai ZJ, Li SR, Xiang YQ, Guo HL, Hou YZ, Li ZB, Li ZJ, Tao YF et al: Lifetime prevalence of suicidal ideation, suicide plans and attempts in rural and urban regions of Beijing, China. Aust Nz J Psychiat 2009, 43(2):158-166.

23. Hajian-Tilaki K: Sample size estimation in epidemiologic studies. Caspian J Intern Med 2011, 2(4):289-298.

24. Serati M, Redaelli M, Buoli M, Altamura AC: Perinatal Major Depression Biomarkers: A systematic review. J Affect Disord 2016, 193:391-404.

25. Miksic S, Miskulin M, Juranic B, Rakosec Z, Vcev A, Degmecic D: Depression and Suicidality during Pregnancy. Psychiatr Danub 2018, 30(1):85-90.

26. Gavin NI, Gaynes BN, Lohr KN, Meltzer-Brody S, Gartlehner G, Swinson T: Perinatal depression: a systematic review of prevalence and incidence. Obstet Gynecol 2005, 106(5 Pt 1):1071-1083.

27. Hawton K, Casanas ICC, Haw C, Saunders K: Risk factors for suicide in individuals with depression: a systematic review. $J$ Affect Disord 2013, 147(1-3):17-28.

28. Ivbijaro G, Kolkiewicz L, Goldberg D, Riba MB, N'Jie I NS, Geller J, Kallivayalil R, Javed A, Svab I, Summergrad P et al: Preventing suicide, promoting resilience: Is this achievable from a global perspective? Asia Pac Psychiatry 2019, 11(4):e12371.

29. Cheung VHM, Chan CY, Au RKC: The influence of resilience and coping strategies on suicidal ideation among Chinese undergraduate freshmen in Hong Kong. Asia Pac Psychiatry 2019, 11(2):e12339.

30. Gandhi SG, Gilbert WM, McElvy SS, El Kady D, Danielson B, Xing G, Smith LH: Maternal and neonatal outcomes after attempted suicide. Obstet Gynecol 2006, 107(5):984-990.

31. Mota NP, Chartier M, Ekuma O, Nie Y, Hensel JM, MacWilliam L, McDougall C, Vigod S, Bolton JM: Mental Disorders and Suicide Attempts in the Pregnancy and Postpartum Periods Compared with Non-Pregnancy: A Population-Based Study. Can J Psychiatry 2019, 64(7):482-491.

32. Yang XL: Evaluation of psychological status and corresponding nursing of psychological disorder among parturient women. Journal of Qiqihar Medical College 2007, 28(5):601-602.

33. Zhong QY, Gelaye B, Rondon MB, Sanchez SE, Simon GE, Henderson DC, Barrios YV, Sanchez PM, Williams MA: Using the Patient Health Questionnaire (PHQ-9) and the Edinburgh Postnatal Depression Scale (EPDS) to assess suicidal ideation among pregnant women in Lima, Peru. Arch Womens Ment Health 2015, 18(6):783-792.

34. Hunter A, Tussis $L$, MacBeth A: The presence of anxiety, depression and stress in women and their partners during pregnancies following perinatal loss: A meta-analysis. J Affect Disorders 2017, 223:153-164.

35. Volgsten H, Jansson C, Svanberg AS, Darj E, Stavreus-Evers A: Longitudinal study of emotional experiences, grief and depressive symptoms in women and men after miscarriage. Midwifery 2018, 64:23-28.

36. Mourady D, Richa S, Karam R, Papazian T, Moussa FH, El Osta N, Kesrouani A, Azouri J, Jabbour H, Hajj A et al: Associations between quality of life, physical activity, worry, depression and insomnia: A cross-sectional designed study in healthy pregnant women. Plos One 2017, 12(5). 
37. Ritsner M, Modai I, Endicott J, Rivkin O, Nechamkin Y, Barak P, Goldin V, Ponizovsky A: Differences in quality of life domains and psychopathologic and psychosocial factors in psychiatric patients. J Clin Psychiatry 2000, 61(11):880-889; quiz 890.

38. Singleton SS: Depression and quality of life: a patient's perspective. J Clin Psychiatry 2001, 62 Suppl 26:22. 